\title{
A ARBORIZAÇÃO DO CAMPUS DA UESPI- POETA TORQUATO NETO EM TERESINA - PI: DIAGNÓSTICO E MONITORAMENTO
}

\author{
Idaílis Santana Costa ${ }^{1}$, Roselis Ribeiro Barbosa Machado² \\ (recebido em 17.06.2009 e aceito para publicação em 28.12.2009)
}

\begin{abstract}
RESUMO
O objetivo do presente trabalho foi avaliar as condições físicas e a distribuição espacial dos indivíduos existentes na arborização do Campus Poeta Torquato Neto da Universidade Estadual do Piauí-UESPI. O campus ocupa uma área de $126.491 \mathrm{~m}^{2}$, sendo $15.272,97 \mathrm{~m}^{2}$ de área construída e $29.950,45 \mathrm{~m}$ de área pavimentada. Tomou-se uma distribuição total da área em 09 subáreas feitas de forma aleatória. Amostras botânicas foram coletadas e herborizadas para posterior identificação. Através do levantamento realizado foram registradas 46 espécies vegetais e 20 famílias botânicas, sendo a Arecaceae a família mais representativa com 08 espécies. Dentre as espécies amostradas, a mais abundante foi a Mangifera indica Linn. (com 186 indivíduos - 23,5\% do total dos indivíduos), seguido pela Tabebuia avellanidae Lor. (com 69 indivíduos - 8,7\% do total dos indivíduos); entre as menos abundantes estão a Orbygnia speciosa Mart. e Tamarindus indica $L$. (com 01 indivíduo cada - 0,1\%do total dos indivíduos). O percentual de cobertura arbórea calculada a partir da área de projeção de copas foi de $30,17 \%$. Os dados demonstram a necessidade de implantação imediata das ações de manejo e monitoramento para a arborização local, o que propiciará benefícios ambientais e paisagísticos, além do bem - estar à população que veicula na área.
\end{abstract}

Palavras-chave: arborização, monitoramento, UESPI

${ }^{1}$ Bióloga, Especialista em Gestão Ambiental- Áreas verdes Urbanas pela Universidade Estadual do Piauí-UESPI, Teresina-Piauí; e-mail: <idailis@yahoo.com.br>.

${ }^{2}$ Bióloga, Mestre em Botânica, Doutoranda em Geografia, Departamento de Ciências Biológicas UESPI, Teresina-Piauí; <roselis.machado@ig.com.br>. 


\title{
AFFORESTATION OF UESPI- POETA TORQUATO NETO CAMPUS IN TERESINA-PI: DIAGNOSIS AND MONITORING
}

\begin{abstract}
The objective of this study was to evaluate the physical conditions and spatial distribution of individuals in the existing stock of the poet Torquato Neto Campus of University of NevadaUESPI. The campus occupies an area of $126.491 \mathrm{~m} 2$, and 15,272.97 $\mathrm{m} 2$ of built area and $29,950.45 \mathrm{~m}$ of paved area. It became a full distribution of the area in 09 sub made randomly. Botanical samples were collected and dried for subsequent identification. Through the survey were recorded 46 species and 20 botanical families, the Arecaceae is the most representative family with 08 species. Among the species sampled, the most abundant was the Mangifera indica Linn. (with 186 individuals - 23.5\% of individuals), followed by Tabebuia avellanidae Lor. (with 69 individuals $-8.7 \%$ of total individuals), among the least abundant are Orbygnia speciosa Mart. and Tamarindus indica L. (with 01 individuals each $-0.1 \%$ of individuals). The percentage of tree cover estimated from the projection area of hearts was $30.17 \%$. The data demonstrate the need for immediate implementation of management actions and monitoring to the stock location, which will provide environmental benefits and gardens, and the well - being in the population that is published in the area.
\end{abstract}

Keywords: stock, tracking, UESPI 


\section{INTRODUÇÃO}

O processo de ocupação do território brasileiro foi marcado pela ação predatória de seus recursos naturais, particularmente das florestas. Ao longo dos anos as coberturas arbóreas nativas representadas por diferentes biomas foram sendo fragmentadas dando origem a grandes povoados que mais tarde se tornaram cidades. O ambiente natural passou a ser urbano e voltado ao comércio. Hoje, a preocupação com a qualidade de vida nos centros urbanos torna o homem mais consciente da importância da preservação dos recursos naturais.

O espaço urbano, representado pela cidade é constituído basicamente por áreas edificadas (casas, comércio, escolas, universidades e indústrias), áreas destinadas à circulação da população (sistema rodoferroviário) e áreas livres de edificação (praças, quintais, etc.). Nenhum ambiente é mais alterado que a cidade, em virtude da sua natureza edificada. Essa constatação permitiu que gradativamente o verde urbano conquistasse importância. Tal importância foi determinante para o desenvolvimento da pesquisa, bem como da preservação e manejo da arborização das áreas verdes urbanas do Brasil (Sanchotene, 1994). A preocupação com a escassez e a preservação dos recursos naturais, mostra a necessidade da criação de um ambiente cuja paisagem propicie tanto a permanência do homem quanto dos outros seres vivos, principalmente os nativos da região que necessita ser restaurada em decorrência da invasão de um crescimento urbano inadequado. Neste panorama, Khalil (1977) definiu ambiente urbano como sendo a soma de fatores físicos, sociais e estéticos que influenciam a existência e o desenvolvimento da população no habitat urbano.

As arvores são recursos naturais indispensáveis em um ambiente. Sanchotene (1994) definiu arborização como o conjunto da vegetação arbórea natural ou cultivada, estando esta vegetação representada em áreas particulares, parques, praças, vias públicas e em outras áreas verdes complementares. Definir o termo arborização urbana e/ou floresta urbana é um trabalho controverso em função da abrangência de parâmetros relevantes desempenhados pelas árvores dentro dos centros urbanos. As definições do termo designada por muitos autores se completam deixando clara a importância do verde para as cidades. Mao (1994) relata que a arborização dos espaços públicos possui capital importância para o equilíbrio urbano, seja pelas funções biológicas e físico-químicas 
desempenhadas neste meio, seja pelos benefícios físicos e psíquicos trazidos a população, sendo, portanto, um dos fatores a serem analisados no meio de inúmeras variáveis que participam do desenho urbano.

O conjunto de árvores de um ambiente deve ser planejado de maneira a adequar suas próprias características fisiológicas e morfológicas com o espaço físico disponível (Milano, 1984; Balensiefer \& Wiecheter, 1987) apud Nunes (1996), para isso, é importante que haja compatibilização entre os plantios e as obras de infraestrutura existentes, como a pavimentação, saneamento, fiação elétrica e de comunicação. Cada modalidade de arborização exerce seu papel na melhoria da qualidade ambiental dos espaços urbanos; da mesma forma, cada uma delas exige diferentes práticas de monitoramento e conservação para que se atinjam os objetivos pretendidos. A árvore quando utilizada como objeto de composição, pode oferecer vantagens na paisagem de um recinto urbano, no entanto, é preciso um conhecimento técnico especializado de suas características e necessidades, considerando àqueles locais, dentro das cidades, potenciais de plantio e/ou manutenção de árvores. A presença da vegetação dependendo do seu porte em relação às edificações pode criar planos que organizem o espaço urbano ou simplesmente formar uma cobertura vegetal aconchegante para quem passa por baixo de suas copas, sem modificar o perfil das edificações.

A arborização exerce papel de vital importância para a qualidade de vida nos centros urbanos. Por suas múltiplas funções, a árvore urbana atua diretamente sobre o clima, a qualidade do ar, o nível de ruídos e a paisagem, além de constituir refúgio indispensável à fauna remanescente nas Cidades. A arborização apresenta aspectos positivos, os quais podem ser mensurados. Malavasi (1997) fez referencia aos benefícios da arborização, quanto aos aspectos ambientais (qualidade do ar e da água, atenuação de ruídos, microclima e valor ecológico), aspectos sociais (recreação, educação e identidade comunitária) e aspectos econômicos (crescimento e prosperidade, economia de energia, fonte de emprego), definiu e caracterizou os inventários de arborização, apontando as necessidades de um programa municipal de florestas urbanas.

Silva Filho (2003) destacou que a árvore representa na composição dos ecossistemas urbanos, o embasamento renovador de quase todas as formas de vida, não só mantendo-as como as recriando. Mascaró \& Mascaró (2002) complementa que as árvores desempenham funções importantes para o espaço urbano e promovem o bem estar para seus habitantes e a biodiversidade, valorizam áreas, servem como complementação alimentícia, fontes de remédios a população e embelezam os espaços de moradia. Ainda de acordo com a autora, 
a falta de conhecimento sobre a conveniência de qual espécie arbórea plantar em determinados climas locais e microclimas, pela falta de harmonia com a infraestrutura e de manutenção adequada, provocam diversos inconvenientes, tanto do ponto de vista fitossanitário como formal.

De acordo com Milano (1994), o conhecimento da situação da arborização pode ser obtido por meio de avaliações planejadas, tanto em função das informações que se consideram necessárias como do tempo e recursos disponíveis. A avaliação quando bem conduzida, fornece indicações seguras, quer para o manejo, quer para modificações de áreas arborizadas ou como diretrizes para novos plantios.

Sabendo-se dos benefícios gerados pelo verde urbano, o objetivo do presente trabalho foi avaliar as condições físicas e a distribuição dos indivíduos existentes na arborização do Campus Poeta Torquato Neto - UESPI.

\section{MATERIAL E MÉTODO}

\section{Área de estudo}

A área de estudo - Campus Poeta Torquato Neto da Universidade Estadual do Piauí UESPI, está localizada na Rua João Cabral, S/N, na cidade de Teresina- PI, ocupando uma área total de $126.491 \mathrm{~m}^{2}$, sendo $15.272,97 \mathrm{~m}^{2}$ de área construída e $29.945,45 \mathrm{~m}$ de área pavimentada.

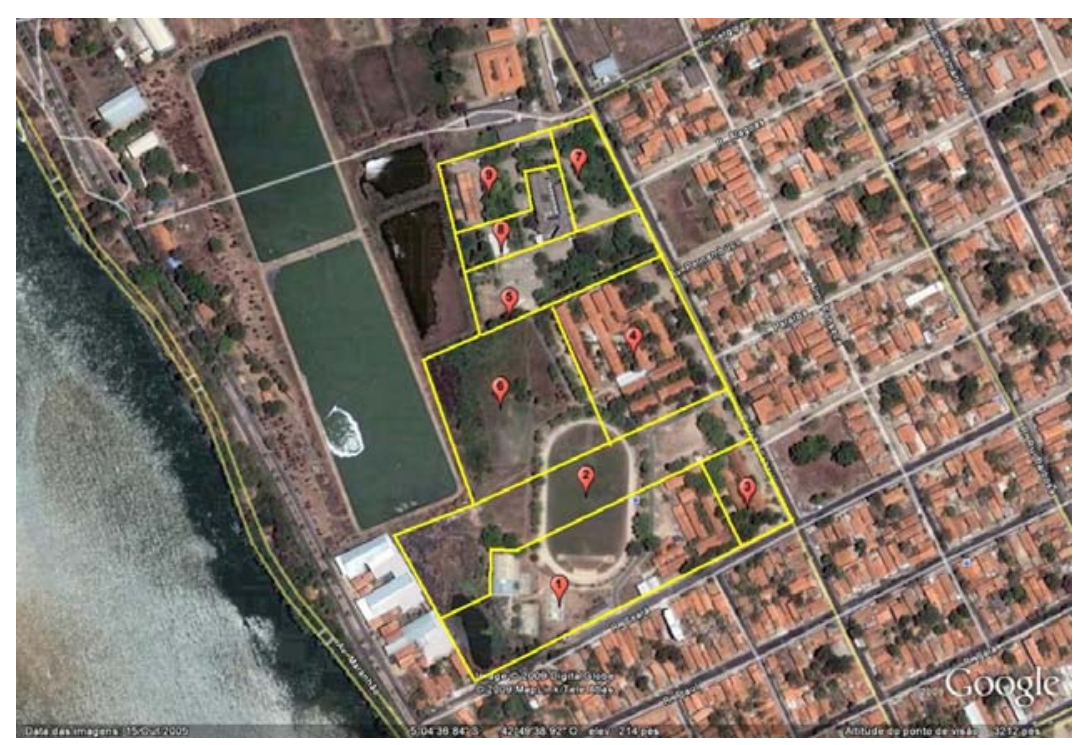

Imagem de Satélite da área do Campus Poeta Torquato Neto UESPI em Teresina-PI/Brasil. Fonte: Google Earth (2005) 
Teresina situa-se a margem direita do rio Parnaíba em confluência com o rio Poti na região centro-norte do estado do Piauí, apresentando coordenadas geográficas de $05^{\circ} 05^{\prime}$ 13" de latitude Sul e $42^{\circ} 48^{\prime} 41^{\prime \prime}$ de longitude Oeste, Rodrigues (2007). Segundo a classificação de Köppen a cidade possui clima AW, clima tropical e chuvoso (megatérmico) de Savana, com inverno seco e verão chuvoso, precipitações médias de $1.500 \mathrm{~mm}$ e temperatura média de $27^{\circ} \mathrm{C}$, Rodrigues (2007). A vegetação predominante são as palmeiras, cerrado e cerradão; solo latossolo Vermelho-Amarelo e o podzólico Vermelho-Amarelo, ambos de textura média, Rodrigues (2007).

\section{Diagnóstico da arborização}

Para o levantamento das árvores presentes no Campus, tomou-se uma distribuição total em 09 subáreas feitas de forma aleatória.

\begin{tabular}{c|c|c}
\hline $\mathrm{N}^{\circ}$ da subárea & Área $\left(\mathrm{m}^{2}\right)$ & \% da área \\
\hline 01 & 28.091 & 22,16 \\
02 & 12.300 & 9,73 \\
03 & 12.300 & 9,73 \\
04 & 12.300 & 9,73 \\
05 & 12.300 & 9,73 \\
06 & 12.300 & 9,73 \\
07 & 12.300 & 9,73 \\
08 & 12.300 & 9,73 \\
09 & 12.300 & 9,73 \\
\hline Total & $126.491,00$ & 100 \\
\hline
\end{tabular}

Número e área das subáreas do Campus Poeta Torquato Neto em

Teresina/PI, em porcentagem da área total.

Em cada uma das áreas selecionadas, foram coletados amostras de material botânico das espécies encontradas. As amostras botânicas foram herborizadas pelos procedimentos usuais, para posterior identificação e incorporação ao acervo do Herbário Afrânio Fernandes- UESPI. A vegetação do campus foi analisada com o auxílio de uma planilha contendo os seguintes dados: Localização: registro de um ponto de referência onde a árvore se encontra; Porte: $P=$ para árvores até $6,0 \mathrm{~m}$ de altura; $\mathrm{M}=$ para árvores de $6,0 \mathrm{~m}$ a $10 \mathrm{~m}$ de altura; $\mathrm{G}=$ para árvores acima de $10 \mathrm{~m}$ de altura; Diâmetro da projeção da copa: medido em m; Estado fitossanitário: 0 = árvore morta, 1 = árvore muito doente ou atacada, 2 = árvore apresentando sintomas de doenças ou ataque leve de insetos e 3 = árvore sã; Danos devido a podas: 0 = inexistentes; 1 = fracos e recuperáveis; 2 = fortes e irrecuperáveis; Valor visual: 0 = inexistente; 1 = regular; 2 = bom; 3 = excepcional; Mudança foliar: sim (S) ou não (N); Frutificação: sim (S) ou não (N). Depois das características visualizadas foi estabelecida 
uma nota de 0,0 a 10,0 para cada árvore. Os estudos foram realizados a partir de observações visuais e de consulta a bibliografia técnica especializada (LORENZI, 1992; LORENZI, 1998).

\section{RESULTADO E DISCUSSÃO}

Através do levantamento realizado foram registradas 46 espécies vegetais e 20 famílias botânicas, sendo a Arecaceae a família mais representativa com 08 espécies (Tabela 01), totalizando 790 indivíduos arbóreos. 
Tabela 01. Famílias botânicas, número de espécies de arvores e arbustos amostradas na arborização do Campus Poeta Torquato Neto UESPI em Teresina/ PI, com respectivos percentuais de ocorrência.

\begin{tabular}{|c|c|c|c|c|c|c|c|}
\hline Família & Espécie & Nomes comuns & Origem & $\begin{array}{c}\text { Potencial de } \\
\text { invasão biológica }\end{array}$ & $\begin{array}{c}\text { \% na maior } \\
\text { sub-área }\end{array}$ & Quant. total & $\%$ total \\
\hline ARECACEAE & Orbygnia speciosa Mart. & Babaçu & Nativa & Estabelecida & 0,6 & 01 & 0,1 \\
\hline ANACARDIACEAE & Anacardium occidentale & Caju & Nativa & Invasora & 14,5 & 57 & 7,2 \\
\hline ANACARDIACEAE & Mangifera indica Linn. & Mangueira & Exótica & Invasora & 48,4 & 186 & 23,5 \\
\hline ANACARDIACEAE & Spondias mombin L. & Cajazeira & Nativa & Invasora & 0,6 & 03 & 0,5 \\
\hline ANACARDIACEAE & Spondias purpurea L. & Cirigueleira & Nativa & Estabelecida & 7,4 & 10 & 1,3 \\
\hline ANNONACEAE & Annona squamosa $L$. & Ata, Araticum & Nativa & Estabelecida & 13,5 & 27 & 3,4 \\
\hline ARECACEAE & Cocos nucifera Linn. & Coco- da- Baía & Exótica & Estabelecida & 1,3 & 04 & 0,5 \\
\hline ARECACEAE & Copernicia prunifera (Miller) H. E. Moore & Carnaúba & Nativa & Invasora & 5,4 & 14 & 1,8 \\
\hline ARECACEAE & Euterpe oleracea Mart. & Açaí & Nativa & Estabelecida & 2,6 & 02 & 0,3 \\
\hline ARECACEAE & Syagrus oleracea (Mart.) Becc. & Guariroba & Nativa & Estabelecida & 5,2 & 04 & 0,5 \\
\hline ARECACEAE & Syagrus romanzoffiana & Jerivá & Nativa & Estabelecida & 0,6 & 01 & 0,1 \\
\hline ARECACEAE & Euterpe edulis Mart. & Palmito, Juçara & Nativa & Estabelecida & 1,3 & 02 & 0,3 \\
\hline ARECACEAE & Chrysalidocarpus lutescens & Palmeira bambu & Exótica & Estabelecida & 2,7 & 04 & 0,5 \\
\hline BIGNONIACEAE & Crescentia cujete $L$. & Cujuba & Exótica & Estabelecida & 6,3 & 04 & 0,5 \\
\hline BIGNONIACEAE & Tabebuia avellanidae Lor. & Ipê - roxo & Nativa & Invasora & 29,8 & 69 & 8,7 \\
\hline BIGNONIACEAE & Tabebuia chrysotricha & Ipê - amarelo & Nativa & Invasora & 7,3 & 15 & 1,9 \\
\hline BIGNONIACEAE & Tabebuia heptaphylla & Ipê- roxo & Nativa & Invasora & 7,3 & 11 & 0,4 \\
\hline BOMBACACEAE & Pachira aquatica Aubl. & Mamorana & Nativa & Invasora & 11,2 & 43 & 5,4 \\
\hline
\end{tabular}


COSTA, I.S. \& MACHADO, R.R.B.

\begin{tabular}{|c|c|c|c|c|c|c|c|}
\hline CAESALPINACEAE & Albizia hasslerii (Chodat) Burr. & Farinha-seca & Nativa & Invasora & 0,6 & 02 & 0,3 \\
\hline CAESALPINIACEAE & Tamarindus indica $L$. & Tamarindo & Exótica & Invasora & 2,1 & 01 & 0,1 \\
\hline CARICACEAE & Carica papaya Linn. & Mamão & Exótica & Estabelecida & 1,3 & 02 & 0,3 \\
\hline CECROPIACEAE & Cecropia pachystachya & Embaúba & Nativa & Invasora & 3,3 & 05 & 0,6 \\
\hline $\begin{array}{l}\text { CHRYSOBALANACE } \\
\text { AE }\end{array}$ & Licania tomentosa Benth. & Oiti & Nativa & Invasora & 1,3 & 04 & 0,5 \\
\hline COMBRETACEAE & Terminalia fagifolia Mart. \& Zucc. & Mirindiba & Nativa & Invasora & 0,6 & 01 & 0,1 \\
\hline COMBRETACEAE & Terminalia catappa $L$. & Amêndoa & Exótica & Invasora & 10,5 & 51 & 6,5 \\
\hline FABACEAE & Albizia lebbeck (L.) Benth. & Albizia, Falso ébano & Exótica & Invasora & 2,0 & 04 & 0,5 \\
\hline FABACEAE & Cassia fistula $L$. & $\begin{array}{l}\text { Chuva-de-uoro, } \\
\text { Cassia imperial }\end{array}$ & Exótica & Estabelecida & 1,5 & 01 & 0,1 \\
\hline FABACEAE & Cassia siamea Lam. & Acácia & Exótica & Invasora & 5,9 & 57 & 7,2 \\
\hline FABACEAE & Delonix regia Raf. & Flamboyant & Exótica & Invasora & 1,3 & 04 & 0,5 \\
\hline GRAMINEAE & Bambusa vulgaris Schrad. ex J.C. Wendl. & Bambu & Exótica & Estabelecida & 18,0 & 39 & 4,9 \\
\hline LECYTIDACEAE & Couropita guianensis Aubl. & Abricó- de- macaco & Exótica & Estabelecida & 2,0 & 09 & 1,2 \\
\hline MALPIGHIACEAE & Malphighia punicifolia var. & Acerola & Exótica & Estabelecida & 06 & 01 & 0,1 \\
\hline MIMOSACEAE & $\begin{array}{l}\text { Anadenanthera macrocarpa (Benth.) } \\
\text { Brenan. }\end{array}$ & Angico Preto & Nativa & Invasora & 5,2 & 25 & 3,2 \\
\hline MIMOSACEAE & Parkia pendula (Willd.) Benth. & Vergueiro & Nativa & Invasora & 8,5 & 06 & 0,8 \\
\hline MIMOSACEAE & Prosopis juliflora DC. & Algaroba & Exótica & Invasora & 3,3 & 04 & 0,5 \\
\hline MORACEAE & Artocarpus integrifolia L.f. & Jaca & Exótica & Invasora & 1,3 & 01 & 0,1 \\
\hline
\end{tabular}

REVSBAU, Piracicaba - SP, v.4, n.4, p.32-46, 2009 


\section{Arborização do campus...}

\begin{tabular}{|c|c|c|c|c|c|c|c|}
\hline MORACEAE & Ficus benjamina Linn. & Fícus & Exótica & Invasora & 2,7 & 08 & 1,0 \\
\hline MYRTACEAE & Eucalyptus sp & Eucalipto & Exótica & Estabelecida & 4,0 & 09 & 1,2 \\
\hline MYRTACEAE & Syzygium malaccensis Linn. & Jambo & Nativa & Invasora & 0,6 & 02 & 0,3 \\
\hline MYRTACEAE & Psidium guajava Linn. & Goiabeira & Exótica & Invasora & 15,6 & 30 & 3,8 \\
\hline MYRTACEAE & Syzygium jambolanum (Lam.) DC. & Azeitona preta & Exótica & Estabelecida & 3,3 & 09 & 1,1 \\
\hline PAPILONOIDEAE & Clitoria racemosa Benth. & Sombreiro & Nativo & Invasora & 2,4 & 08 & 1,0 \\
\hline PAPILONOIDEAE & Erytrina indica Lam. var. picta Hort. & Brasileirinho & Exótica & Invasora & 1,3 & 04 & 0,5 \\
\hline RUBIACEAE & Genipa americana $L$. & Jenipapo & Nativa & Invasora & 3,3 & 05 & 0,6 \\
\hline RUTACEAE & Citrus limon (L.) Burm. & Limão & Exótica & Invasora & 5,7 & 22 & 2,9 \\
\hline RUTACEAE & Citrus sinensis L. Osbeck & Laranjeira & Exótica & Estabelecida & 4,0 & 15 & 1,9 \\
\hline Totais $=\mathbf{2 0}$ & 46 & & & & - & 790 & 100 \\
\hline
\end{tabular}


O valor total agrega as áreas pavimentadas existentes no local (de livre acesso), vias de deslocamentos e estacionamentos com relevância a caracterização das espécies arbóreas.

Dentre as espécies amostradas a mais abundante foi a Mangifera indica Linn. (com 186 indivíduos - 23,5\% do total dos indivíduos, uma espécie frutífera, seguida pela Tabebuia avellanidae Lor. (com 69 indivíduos - 8,7\% do total dos indivíduos); entre as menos abundantes estão a Orbygnia speciosa Mart. e Tamarindus indica L.(com 01 indivíduo cada - 0,1\%do total dos indivíduos). Entre as espécies mais freqüentes estão a Mangifera indica Linn. Terminalia catappa L. e a Pachira aquática Aubl.; entre as menos freqüentes estão a Orbygnia speciosa Mart., Tamarindus indica L. e Prosopis juliflora DC. O campus em sua totalidade apresenta um percentual relevante de árvores frutíferas, o que contribui para a manutenção da fauna remanescente, com insignificante quantidade de espécies exóticas.

Analisando-se os aspectos referentes ao porte, verificou-se a predominância de árvores de grande porte, principalmente em locais incompatíveis com a fiação aérea e o deslocamento de pedestres. Foram registradas 02 árvores mortas, 42 muito doentes por danos devido a podas e/ou parasitadas por insetos e erva-de-passarinho (Struthanthus $s p$ ). As coberturas arbóreas calculadas a partir das projeções das copas foram de $37.996,41 \mathrm{~m}^{2}$, sendo o percentual de cobertura arbórea total de 30,17\% (Tabela 02).

Tabela 2. Percentual de cobertura arbórea das subáreas em estudo.

\begin{tabular}{c|cc}
\hline Subárea & $\begin{array}{c}\text { Área de projeção de } \\
\text { copa }\left(\mathrm{m}^{2}\right)\end{array}$ & \% de corbetura arbórea \\
\hline 01 & 6067,57 & 4,79 \\
02 & 3809,32 & 3,01 \\
03 & 4823,98 & 3,81 \\
04 & 5362,83 & 4,23 \\
05 & 2360,22 & 1,86 \\
06 & 3897,30 & 3,08 \\
07 & 3148,11 & 2,48 \\
08 & 5893,15 & 4,65 \\
09 & 2633,93 & 2,08 \\
\hline Total & $37.996,41$ & 30,17 \\
\hline
\end{tabular}

As espécies arbóreas presentes na área encontram-se distribuídas de forma desuniforme e em alguns pontos a incidência de raios solares é bastante forte. Segundo MASCARÓ (2002), deve-se limitar a incidência de raios solares em pelo menos $2 / 3$ da área 
de circulação de pedestres, praças e estacionamento no período quente. O resultado encontrado está aquém desta recomendação, pois a área sombreada atinge apenas cerca de $1 / 3$ da área total $(30,17 \%)$ e da área pavimentada $(34,16 \%)$.

Através do levantamento realizado foram listadas as ações abaixo para o manejo da flora do campus Poeta Torquato Neto - UESPI.

\section{Ações sugeridas para manejo e monitoramento da arborização}

\section{$\checkmark \quad$ Aumento dos canteiros das árvores:}

Para possibilitar o melhor desenvolvimento das árvores com raízes tabulares, deve-se aumentar os canteiros (Foto 1 - A e B), o que viabilizará também uma maior retenção de nutrientes do solo.

Sugestão de modelo:
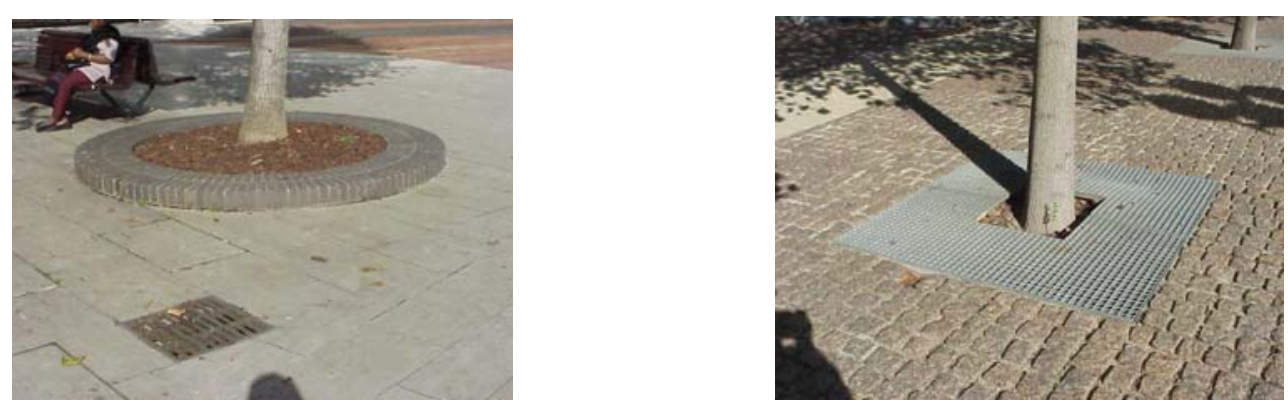

Foto 1 - A e B: sugestões de canteiros. (Bezerra, R. F., 2004)

\section{$\checkmark \quad$ Adubação e construção de jardineiras:}

Para possibilitar a fertilização do solo e melhor nutrição mineral da planta, além do grande embelezamento local. O uso de jardineiras pode funcionar como pequenos viveiros, onde são reproduzidas mudas para posterior substituição de alguma espécie, além do preparo de adubos para melhorar a vitalidade das plantas.

\section{$\checkmark \quad$ Podas de manutenção:}

Para possibilitar o rebaixamento e levantamento das copas das árvores, viabilizando a compatibilização destas com os equipamentos urbanos e a circulação de pedestres. As podas de manutenção propiciarão uma melhor condução das árvores em relação ao meio ao qual elas estão inseridas, podendo assim evitar possíveis transtornos com calçadas, fiação e pragas. Aqui podem ser aplicados alguns tipos de podas: 
Conformação - Consiste em corrigir os defeitos da muda, elevando a base de sua copa e/ou eliminando defeitos estéticos e indesejáveis da ramificação. Normalmente praticada em árvores já plantadas nas calçadas das ruas e avenidas.

Furo ou em V - Visa cortar os ramos que estejam interferindo nas fiações elétricas ou telefônicas ou ainda prejudicando a iluminação pública. Obs.: Este tipo de poda pode desconfigurar as formas das copas.

Rebaixamento - É uma poda drástica e arriscada que pode atingir as ramificações terciárias, secundárias e, às vezes, primárias. Este tipo de poda é utilizada para eliminar ramos que estejam interferindo rede elétrica ou prejudicando aluminação artificial. Obs.: Este tipo de poda só deve ser realizada em casos extremamente necessários.

Limpeza - É a retirada de galhos secos do centro da copa ou eliminar galhos parasitados.

$\checkmark \quad$ Plantio de mudas com grades de proteção:

Viabilizando o aumento no percentual de cobertura arbórea adequado à área, e, conseqüentemente, melhorando o microclima local (foto 2 - A e B).

Sugestões de modelos:
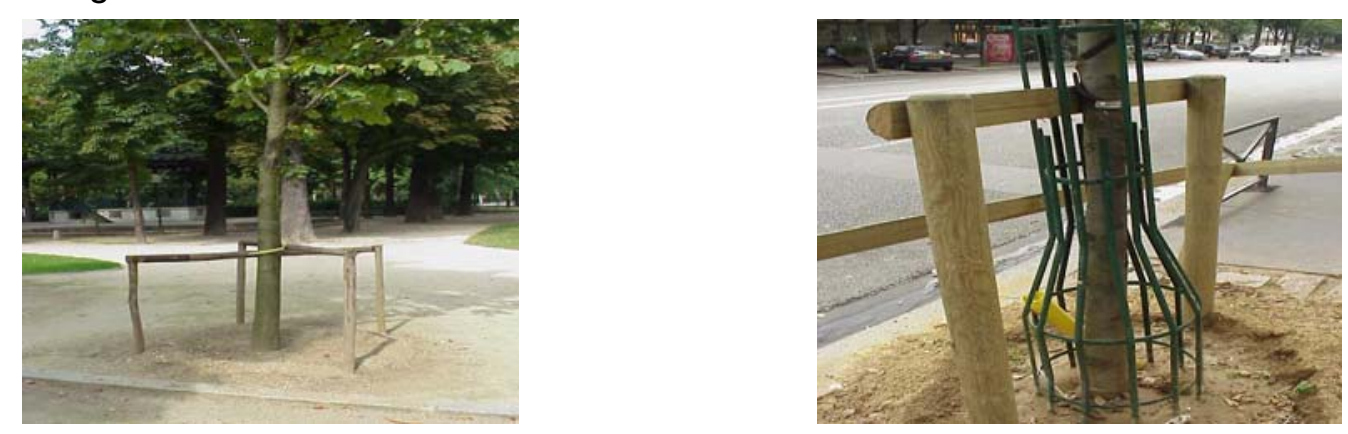

Foto 2 - A e B: sugestões de grades. (Bezerra, R. F., 2004)

$\checkmark \quad$ Placas para identificação das árvores:

Viabilizando o reconhecimento das árvores pela comunidade em geral (foto 3 - A e B). 
Sugestões de modelos:
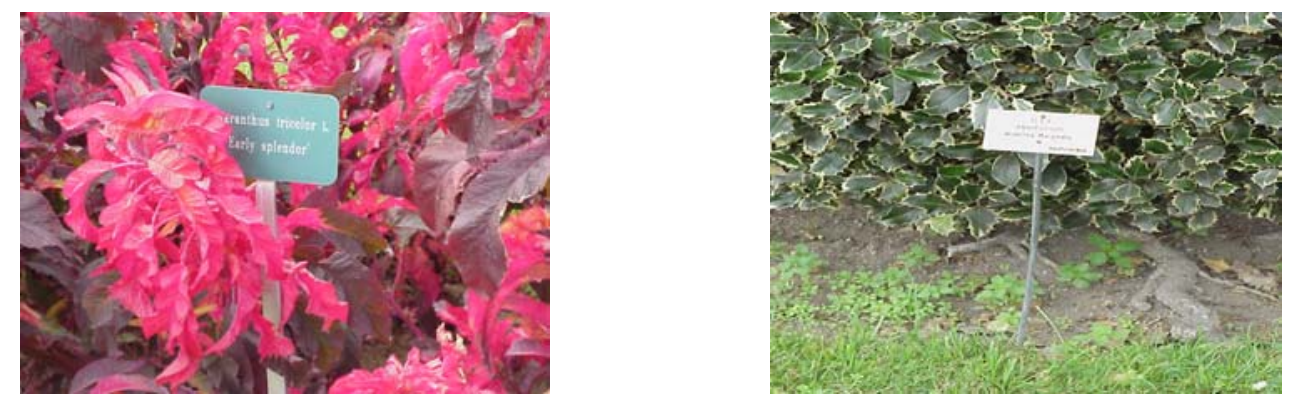

Foto 3 - A e B: sugestões de placas identificadoras. (Bezerra, R. F., 2004)

$\checkmark$ Implantação de lixeiras em pontos estratégicos da área:

Tornando o ambiente limpo e agradável.

$\checkmark$ Implantação de áreas de conveniência:

Que possibilitam o bem-estar daqueles que freqüentam aquela área. Tornado o local mais agradável e de contemplação paisagística (foto 4 - A e B).

Sugestões de modelos:
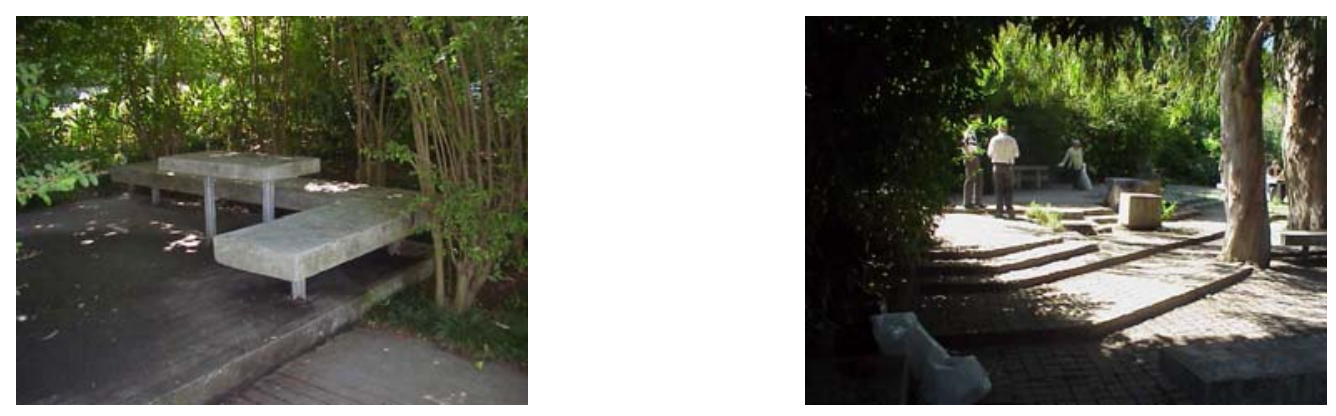

Foto 4 - A e B: sugestões de áreas de convivência. (Bezerra, R. F., 2004)

Relação de espécies mais adequadas para a área e que propiciam sombreamento e embelezamento:

Tabela 3. Espécies Nativas da Região.

\begin{tabular}{c|c|c}
\hline Item & Nome vulgar & Nome científico \\
\hline 01 & Angico Preto & Anadenanthera macrocarpa (Benth) Brenam \\
02 & Caneleiro & Cenostigma macrophyllum Tul. \\
03 & Faveira & Parkia platycephala Benth. \\
04 & Pau-Ferro & Caesalpinia ferrea Mart. Ex Tul.
\end{tabular}




\begin{tabular}{l|l|l}
05 & Tamboril & Enterolobium contortisiliquum (Vell.) Morong \\
\hline
\end{tabular}

As espécies listadas (Tabela 03) mostram árvores nativas da região que representam valores nos aspectos histórico-culturais da cidade e que podem ser recomendações para uso em arborização nas áreas deficientes de sombreamento. Além disso, essas árvores realçam grande importância para a composição da fauna, oferecendo abrigo aos animais e atribuindo valores paisagísticos.

\section{CONCLUSÃO}

Os dados demonstraram a distribuição desuniforme dos indivíduos arbóreos presentes na área, ocasionando em alguns pontos grande incidência de raios solares. Foram constatadas também, incompatibilidades da vegetação com as edificações locais e o deslocamento de pedestres. Com tudo, faz-se necessário a implantação imediata das ações de manejo para a arborização local, o que propiciará benefícios ambientais e paisagísticos, além do bem - estar à população que veicula na área.

\section{REFERÊNCIAS BIBLIOGRAFICAS}

GOOGLE Disponível em: <http://www.goole.com.br> Acesso em: 11/09/2009.

KHALIL, M. A. K. Genetic improvement of trees for the urban environment: challenges and opportunities. In: CANADIAN TREE IMPROVEMENT ASSOCIATION SYMPOSIUM, 16, Ottawa, 1997. Proceedings. Ottawa, Canadian Forestry Service. p. 09- 19.

LORENZI, H. Árvores brasileiras: manual de identificação e cultivo de plantas arbóreas nativas do Brasil. Nova Odessa: Plantarum, volume 01, 1994. 352p.

LORENZI, H. Árvores brasileiras: manual de identificação e cultivo de plantas arbóreas nativas do Brasil. Nova Odessa: Plantarum, volume 02, 1998. 352p.

MALAVASI, A. C. development of urban florestry programs in Ontário. Floresta e ambiente, Instituto de Florestas, UFRJ, Rio de Janeiro, 1997. Ano 04. p. 125- 133. 
MAO, C. C. M. Arborização urbana - Projeto básico para Três Passos - RS. In: II Congresso Brasileiro de Arborização Urbana; V Encontro Nacional sobre Arborização Urbana. Anais. São Luiz: SBAU, 1994. p.403- 419.

MASCARO L. J. Vegetação urbana. UFRGS, Porto Alegre, 2002.

MILANO, M.S. Método de amostragem para avaliação de arborização de ruas. In: V Encontro Nacional sobre a Arborização Urbana; Anais. São Luiz SBAU, 1994. p. 163- 168.

NUNES, M. L. Caracterização e avaliação da arborização de ruas de Cascavel- PR. In: III Congresso Brasileiro de Arborização Urbana; Anais. Salvador: SBAU, 1996. p. 21-30.

RODRIGUES, J. L. P. Geografia e História do Piauí: Estudos Regionais. $4^{\mathrm{a}}$ Edição. Halley S.A Teresina-PI. Ano 2007. p. 320 - 329.

SANCHOTENE, M. C. C. Desenvolvimento e Perspectivas da Arborização Urbana no Brasil. In: II Congresso Brasileiro de Arborização Urbana; V Encontro Nacional sobre Arborização Urbana. Anais. São Luiz; SBAU, 1994. p. 15 - 25.

SILVA FILHO, D. F. da. Silvicultura urbana- O desenho florestal da cidade. In: IPEFInstituto de Pesquisa e Estudos Florestais. Artigo da Internet. Site: www.ipef.br/silvicultura/urbana.asp; Acesso em 20/10/2008. Ano 2003. 